\title{
Efeito do herbicida tembotrione sobre o desenvolvimento da batata
}

\author{
Effect of tembotrione herbicide on potato development
}

\section{Roque Carvalho Dias ${ }^{1 *}$, Amanda Rocha Barbosa ${ }^{2}$, Valesca Pinheiro Miranda ${ }^{2}$, Christiane Augusta Diniz Melo ${ }^{3}$, Daniel Valadão Silva ${ }^{4} \&$ Marcelo Rodrigues Reis ${ }^{2}$}

\author{
${ }^{1}$ Universidade Estadual Paulista, Botucatu, SP, Brasil. *Autor para correspondência: roquediasagro@gmail.com \\ ${ }^{2}$ Universidade Federal de Viçosa, Rio Paranaíba, MG, Brasil. \\ ${ }^{3}$ Universidade Federal do Triângulo Mineiro, Iturama, MG, Brasil. \\ ${ }^{4}$ Universidade Federal Rural do Semi-Árido, Mossoró, RN, Brasil.
}

Submissão: 16/07/2017 / Aceite: 13/06/2018

\begin{abstract}
RESUMO
Os resíduos do herbicida tembotrione no solo, proveniente de cultivos de milho, podem afetar o crescimento de culturas sensíveis, como a batata, em sucessão. Neste sentido, objetivou-se avaliar o efeito do herbicida tembotrione sobre o crescimento e o desenvolvimento da batateira. Realizou-se um experimento de campo em delineamento em blocos casualizados, com quatro repetições. Os tratamentos foram incorporados ao solo um dia antes do plantio da batata cultivar Atlantic e constituídos de quatro doses de tembotrione: 8,$4 ; 16,8 ; 33,6$ e $50,4 \mathrm{~g} \mathrm{ha}^{-1}$, representando 8,$4 ; 16,8 ; 33,6$ e $50 \%$ da dose recomendada para a cultura do milho, e um tratamento controle (sem herbicida e capinada). Aos 60 e 90 dias após o plantio foram avaliadas a massa de matéria fresca de tubérculo (MMFT), o número de hastes $(\mathrm{NH})$, o número de tubérculos (NT) por planta e a massa de matéria seca total (parte aérea + haste) (MMST). A MMFT, NT e MMST decresceram com o aumento das doses do tembotrione, sendo que as maiores reduções encontradas, nas duas épocas avaliadas, foram na dose de $50,4 \mathrm{~g} \mathrm{ha}^{-1}$ i.a. O número de hastes não foi influenciado pelas doses do herbicida tembotrione independente da época avaliada. Os resultados obtidos indicaram que a presença de tembotrione no solo reduziu o crescimento e a quantidade de tubérculos produzidos pela batateira.
\end{abstract}

PALAVRAS-CHAVE: Atlantic, Carryover, Solanum tuberosum L.

\begin{abstract}
Tembotrione herbicide residues from maize crops in the soil can affect the growth of sensitive crops in succession, such as potatoes. In this sense, this study sought to evaluate the residual effect of tembotrione on growth and development of potato plants. A field experiment with randomized blocks design with four replications was conducted. The treatments were incorporated to the soil one day before the planting of the Atlantic potato cultivar and consisted of four doses of tembotrione: $8.4 ; 16.8 ; 33.6$ and $50.4 \mathrm{~g} \mathrm{ha}^{-1}$; representing $8.4 ; 16.8 ; 33.6$ and $50.0 \%$ of the recommended dose for maize, and a control treatment (without herbicide and weeding). Fresh matter mass of tuber (FMMT), number of stems (NS), number of tubers (NT) per plant and total dry matter mass (aerial parts and stem) (DMM) were evaluated at 60 and 90 days. FMMT, NT and DMM decreased with increasing doses of tembotrione. The largest reductions on both evaluated seasons were found for the $50.4 \mathrm{~g} \mathrm{ha}^{-1} \mathrm{i}$.a. dose. The number of stems was not influenced by the tembotrione herbicide doses regardless of evaluated season. The results indicated that the presence of tembotrione in soil reduced growth and the number of tubers produced by potato plants.
\end{abstract}

KEYWORDS: Atlantic, Carryover, Solanum tuberosum L.

\section{INTRODUÇÃO}

A batata é considerada uma olerícola muito relevante, sendo um dos alimentos mais consumidos no mundo, superada apenas pelo trigo, arroz e milho (EVANGELISTA et al. 2011). A produção brasileira no ano de 2016 foi de 3.907 .503 toneladas em uma área cultivada de 134.243 hectares (IBGE 2017).

A interferência de plantas daninhas pode causar prejuízos diretos e indiretos na cultura da batata, podendo reduzir até $60 \%$ da produtividade (ČEPL \& KASAL 2010). O sistema de produção da batata é 
caracterizado por preparo intensivo do solo, uso de altas fertilizações e suprimento constante de água, que também favorecem o estabelecimento de infestações de plantas daninhas de rápido crescimento e desenvolvimento nas áreas cultivadas (REIS et al. 2015).

Assim como na maioria das espécies cultivadas, o controle químico é uma ferramenta imprescindível no manejo integrado de plantas daninhas. No entanto, a presença de resíduos de herbicidas no solo, advindos do cultivo anterior, pode inviabilizar o cultivo de espécies sensíveis em sucessão, assim como reduzir a produtividade e qualidade dos produtos (MANCUSO et al. 2011). Os danos causados são variáveis, dependendo das condições físicas, químicas e de manejo do solo. Ademais, o tempo de permanência de um herbicida no ambiente depende de fatores como propriedades físico-químicas do composto e do solo, condições climáticas, vegetação e outros tipos de cobertura, propriedades biológicas do solo e práticas culturais (PRATA et al. 2003).

A rotação de culturas é prática comumente realizada no Brasil, sendo a batata cultivada em rotação com o cultivo de cereais, a exemplo do milho. O tembotrione lançado comercialmente nos anos de 2007/2008 na Áustria, Hungria, EUA e Brasil (TARARA et al. 2009) é um herbicida seletivo e amplamente utilizado no controle de plantas daninhas na cultura do milho, cujo residual pode interferir no crescimento e desenvolvimento da batata. Sintomas de intoxicação, redução na produtividade e desordens fisiológicas foram observados em batata ao grupo das imidazolinonas e sulfonilureais (EBERLEIN \& GUTTIERE 1994, NOVO \& MIRANDA FILHO 2006) e aos mimetizadores de auxina (WALL 1994), provenientes de herbicidas utilizados em culturas antecessoras ou devido ao efeito de deriva em áreas próximas ao cultivo da batateira.

O herbicida tembotrione, (2-\{2-cloro-4-mesil-3-[(2,2,2-trifluoroetoxi) metil] benzoil\} ciclohexane -1,3diona), apresenta alta solubilidade em água a $20^{\circ} \mathrm{C}(71000 \mathrm{mg} \mathrm{L}-1$ ), pKa de 3,18 (PPDB 2017) meia-vida no solo de 10-14 dias em condições de laboratório e tende a permanecer mais estável em solos com $\mathrm{pH}$ maior (BARCHANSKA et al. 2016). Este herbicida pertence ao grupo das tricetonas e tem como mecanismo de ação a inibição da biossíntese de carotenoides. O processo ocorre pela inibição da enzima hidroxifenilpiruvato-dioxigenase (HPPD), desenvolvendo uma intensa coloração esbranquiçada (CALVAYRAC et al. 2013). Acarreta também estresse oxidativo, resultando na destruição das membranas celulares, levando as plantas sensíveis tratadas à morte (MILLER \& REGEHR 2002, ABIT et al. 2009).

Além disso, as olerícolas em geral são muito sensíveis a resíduos de herbicidas no solo e em condições tropicais (MELO et al. 2016). São poucas as informações sobre o efeito do tembotrione em solos, principalmente, em solos brasileiros, relacionando com seus possíveis efeitos residuais na cultura da batata. Ademais, na bula brasileira deste herbicida não há restrições sobre o cultivo de batata após aplicações do produto na cultura do milho (BAYER CROPSCIENCE 2017). Assim, se faz necessário informações visando recomendações técnicas seguras desse herbicida do ponto de vista agronômico e ambiental.

Diante do exposto, objetivou-se verificar os efeitos de resíduos de tembotrione no solo sobre o crescimento e o desenvolvimento da batateira.

\section{MATERIAL E MÉTODOS}

O experimento foi realizado no município de Serra do Salitre, MG, (196'41"S, 4641'23"W e altitude de 1203 metros). O clima da região enquadra-se no tipo Aw, tropical com estação seca segundo a classificação de Köppen-Geiger. Os dados diários de precipitação pluviométrica (mm) e temperatura $\left({ }^{\circ} \mathrm{C}\right)$ mínima e máxima do ar durante o período de condução do experimento foram agrupados médias semanais e estão demonstrados na Figura 1.

O solo da área experimental é classificado como Latossolo Vermelho-Amarelo (EMBRAPA 2013), textura média (19,4\% de argila, $2,7 \%$ de silte e $77,9 \%$ de areia). Os atributos químicos estão demonstrados na Tabela 1.

O delineamento experimental foi em blocos casualizados, com cinco tratamentos (doses do tembotrione $0,8,4 ; 16,8 ; 33,6$ e 50,4 $\mathrm{g} \mathrm{ha}^{-1}$, representando 8,4; 16,8; 33,6 e 50\% da dose recomendada para a cultura do milho), e um tratamento controle (sem herbicida e capinada), com quatro repetições, totalizando 20 parcelas. Cada parcela experimental foi constituída de 4 linhas com 6 metros de comprimento e a área útil de avaliação de duas linhas centrais de 4 metros de comprimento.

A aplicação do tembotrione foi realizada no dia 09/11/2014 com pulverizador costal pressurizado com $\mathrm{CO}_{2}$ a 2 bar de pressão, com pontas jato plano tipo leque 110-02, com volume de calda de $200 \mathrm{~L}$ ha-1. As doses do herbicida foram aplicadas e incorporadas na camada de solo de $0-30 \mathrm{~cm}$, o plantio após um dia da aplicação teve por objetivo maximizar o contato herbicida-tubérculo. Ademais, não há informações na bula brasileira desse herbicida quanto à existência de restrições para o cultivo da batata após a aplicação deste.

As condições climáticas no momento da aplicação dos tratamentos foram umidade relativa do ar de 
$66,50 \%$, temperatura do ar atmosférico de $23,53^{\circ} \mathrm{C}$ e velocidade do vento de $1,02 \mathrm{~km} \mathrm{~h}^{-1}$.

A cultivar de batata "Atlantic" foi plantada um dia após a aplicação e a incorporação das doses do herbicida, no espaçamento de 0,22 m entre plantas e 0,87 m entre linhas. A adubação de plantio consistiu de $1000 \mathrm{~kg} \mathrm{ha}^{-1}$ de Superfosfato Simples, $1000 \mathrm{~kg} \mathrm{ha}^{-1}$ do formulado $11-52-00,80 \mathrm{~kg} \mathrm{ha}^{-1}$ de cloreto de potássio e $30 \mathrm{~kg} \mathrm{ha}^{-1}$ de Haygran ${ }^{\circledR}(5 \%$ Boro e 10\% Zinco). Foram realizadas duas adubações de coberturas (30 e 50 dias), ambas com $50 \mathrm{~kg} \mathrm{ha}^{-1}$ de ureia e $100 \mathrm{~kg} \mathrm{ha}^{-1}$ de cloreto de potássio.

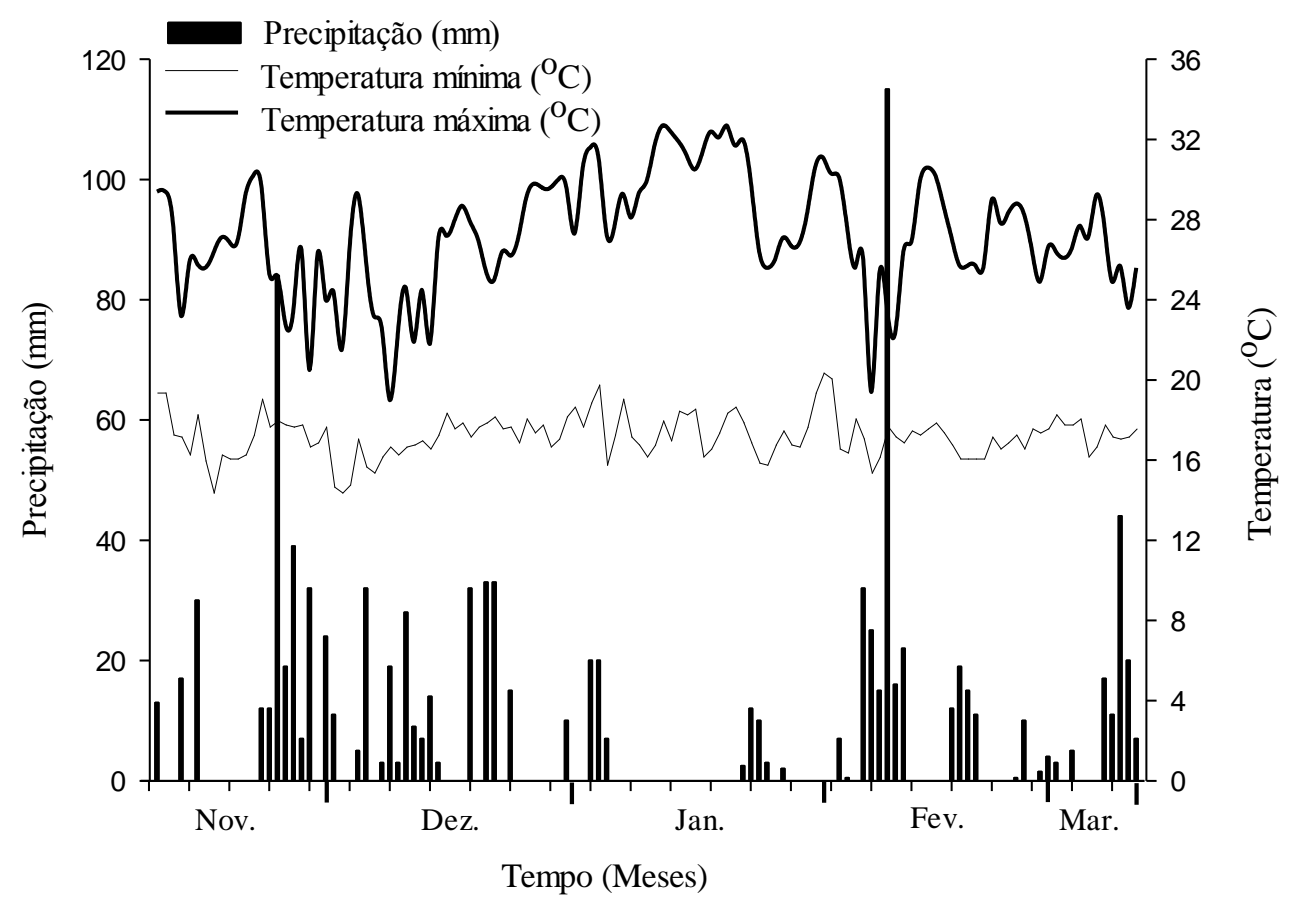

Figura 1. Precipitação pluviométrica diária $(\mathrm{mm})$, temperaturas diárias mínimas e máximas $\left({ }^{\circ} \mathrm{C}\right)$ no período de outubro de 2014 (aplicação do tembotrione) até março de 2015 (colheita da batata). Serra do Salitre, MG.

Figure 1. Daily precipitation $(\mathrm{mm})$, maximum and minimum air temperature $\left({ }^{\circ} \mathrm{C}\right)$ from October 2014 (application of tembotrione) to March 2015 (potato harvest) in the experimental area Serra do Salitre, Minas Gerais, Brazil.

Aos 60 e 90 dias após o plantio (DAP) foram avaliados a massa da matéria fresca dos tubérculos (MMFT) (g/planta); o número de tubérculos por planta (NT); o número de hastes por planta $(\mathrm{NH})$ e a massa da matéria seca total (parte aérea + hastes) (MMST) (g/planta). Para isso, foram coletadas oito plantas ao acaso em cada parcela experimental. Para avaliação da massa da matéria seca total as amostras foram acondicionadas em sacos de papel e levadas para estufa de circulação de ar forçada, com temperatura média de $72{ }^{\circ} \mathrm{C}$, até atingir massa constante, sendo posteriormente pesadas em balança analítica.

Os dados foram submetidos a análise de variância e de regressão $(p<0,05)$, sendo a escolha do modelo baseado no fenômeno biológico, no coeficiente de determinação e na significância dos coeficientes da regressão. As análises foram realizadas com o auxílio do programa estatístico Statistical Analysis System (SAS, versão portable 9.2.1) sendo os gráficos elaborados pelo Sigmaplot versão 12.5.

Tabela 1. Atributos químicos do solo, na camada de 0-0,20 m, presente na área experimental.

Table 1. Chemical soil characteristics on the 0-0.20 m layer in the experimental area.

\begin{tabular}{|c|c|c|c|c|c|c|c|c|c|c|c|c|}
\hline & $P$ & $\mathrm{~K}$ & $\mathrm{Ca}^{+2}$ & $\mathrm{Mg}^{+2}$ & $\mathrm{Al}^{+3}$ & $\mathrm{H}+\mathrm{Al}$ & $t$ & $T$ & V & $\mathrm{m}$ & $\mathrm{MO}$ & P-rem \\
\hline $\mathrm{pH}$ & \multicolumn{3}{|c|}{$\mathrm{mg} \mathrm{dm} \mathrm{m}^{-3}$} & -------. & ------ & ololc $d m$ & ------. & & \multicolumn{2}{|c|}{$\%$} & dag $\mathrm{kg}^{-1}$ & $\mathrm{mg} \mathrm{L}^{-1}$ \\
\hline 6,02 & 5,66 & 0,25 & 1,85 & 0,57 & 0,00 & 3,11 & 2,67 & 5,78 & 46,31 & 0,00 & 2,25 & 38,44 \\
\hline
\end{tabular}

Extratores: $\mathrm{pH}$ - $\mathrm{H}_{2} \mathrm{O}$; P e K - Mehlich 1; Ca, Mg, Al - KCl $1 \mathrm{~mol} \mathrm{~L}^{-1} ; \mathrm{H}+\mathrm{Al}-\mathrm{Ca}(\mathrm{OAc})_{2} 0,5 \mathrm{~mol} \mathrm{~L}^{-1}$.

\section{RESULTADOS E DISCUSSÃO}

A massa da matéria fresca dos tubérculos (MMTF), número de tubérculos (NT) e massa da matéria 
seca total (MMST) foram reduzidas com o aumento das doses do tembotrione em ambas as avaliações, 60 e 90 dias após o plantio (DAP). A maior dose de 50,4 $\mathrm{g}^{-1}$ i.a. acarretou redução de aproximadamente $24 \%$ na massa da matéria fresca dos tubérculos nas duas épocas avaliadas (Figura $2 A$ ). Em relação ao NT (Figura 2B) verificou-se que na dose de $50,4 \mathrm{~g}^{-1}$ i.a. aos 60 e 90 DAP as reduções no número de tubérculos foram de 34,46 e $44,93 \%$, respectivamente, em relação ao tratamento controle. Além disso, o aumento das doses de tembotrione afetou negativamente o acúmulo de massa da matéria seca total em ambas as épocas (Figura 3B), com reduções máximas de 28 e 20\% nas épocas 60 e 90 DAP, respectivamente.
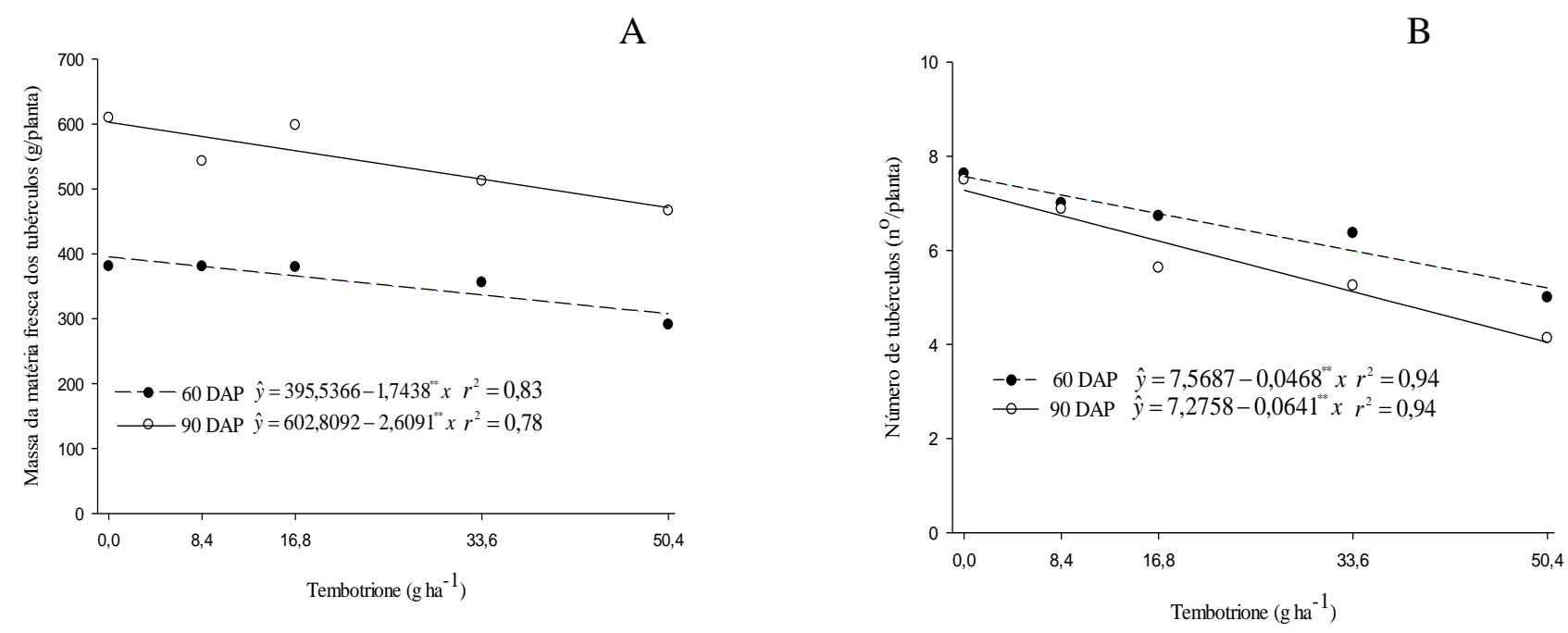

Figura 2. Massa da matéria fresca dos tubérculos (g/planta). (A) número de tubérculos por planta. (B) de batata cultivada em solo com diferentes doses do tembotrione incorporadas.

${ }^{* *}$ significativo a $1 \%$ pelo teste $t$, respectivamente. ${ }^{-}-\mathrm{e}^{-0} 60$ e 90 dias após o plantio (DAP), respectivamente.

Figure 2. Fresh matter mass of tubers (g/plant). (A) number of tubers per plant. (B) number of potatoes grown in soil with different doses of tembotrione incorporated.

${ }^{*} 1 \%$ Significance by $t$ test, respectively. $-\bullet$ and -60 and 90 days after planting (DAP), respectively.

A redução na massa da matéria fresca, número de tubérculos e na massa da matéria seca total devese ao fato da disponibilidade do herbicida no solo, sendo esta governada por fatores como textura, solubilidade e pH. De maneira geral, a maior ligação de uma substância com coloides do solo ocorre por adsorção em superfície, por ligações de hidrogênio e interações de Van der Waals (VIVIAN et al. 2007).

Em solos arenosos e de textura média, há menor disponibilidade de sítios de ligação. Como o herbicida fica menos sorvido, maior a porcentagem disponível na solução do solo e consequentemente maior será a predisposição em afetar a cultura. Além disso, o tembotrione tem a característica de se tornar mais hidrofílico em maiores valores de $\mathrm{pH}$, aumentando a sua solubilidade em água (PPDB 2017). E, por apresentar caráter ácido com característica aniônica, carregado negativamente em solução, pode sofrer repulsão com os grupos negativos na superfície solo, logo, apenas a porção na forma molecular seria adsorvida (TRIGO et al. 2014). Dessa forma, as condições ambientais no presente estudo aparentemente contribuíram para o maior risco em influenciar no crescimento e desenvolvimento da batateira, uma vez que o solo apresentava textura média e pH 6,02, o que implica na predominância da fórmula ionizável, ou seja, mais disponível na solução do solo.

Paralelamente aos fatores associados a disponibilização do herbicida, o fato dos tubérculos serem resultado do acúmulo de fotoassimilados, logo, se houver alguma interferência na fotossíntese em decorrência da ação do herbicida, pode ocorrer diminuição no rendimento e desenvolvimento do tubérculo.

O herbicida tembotrione inibe a enzima hydroxyphenylpyruvate dioxygenase (HPPD) que atua na síntese de carotenoides (MILLER \& REGEHR 2002, ABIT et al. 2009), que por sua vez tem a função de absorver o excesso da luz azul, proteger a clorofila da foto-oxidação e bloquear também parte do transporte de elétrons da fotossíntese, em nível de fotossistema II (PETER \& THORNBER 1991, HESS 2000). Mais de $90 \%$ da massa da matéria seca da planta de batata é derivado da fotossíntese (ZELITCH 1975). Assim, a interferência na síntese dos carotenoides e suas consequências relacionadas à fotossíntese podem 
repercutir diretamente sobre o acúmulo de massa da matéria seca total da planta, podendo representar um fator negativo para o cultivo da batata.

A produção da massa da matéria fresca do tubérculo é uma função da capacidade do dreno e do potencial da fonte, e a produção é reduzida quando um desses fatores é limitado (CONCEIÇÃO et al. 2004). Sendo as folhas o fator fonte, a eficiência na produção de massa de matéria fresca é reduzida parcialmente por mudanças internas que atuem diretamente na eficiência fotossintética. A produção e formação do tubérculo estão relacionadas à manutenção da área fotossintetizante durante o período de crescimento da parte de interesse comercial (LENIS et al. 2006).

Plantas com maior rendimento tiveram maior número de tubérculos e massa média de tubérculos (MARIS 1988). O coeficiente de partição de massa dos tubérculos aumenta progressivamente após o início da tuberização, o que evidencia que a maior parte dos fotoassimilados disponíveis são alocados para 0 crescimento dos tubérculos (SILVA \& PINTO 2005, SILVA et al. 2009). Ademais, no estádio de maturação dos tubérculos, o aumento da massa da matéria fresca é resultado, principalmente, da translocação de materiais da parte aérea (BIEMOND \& VOS 1992).

Em estudos no Canadá, foram constatadas reduções de massa da matéria seca da planta de batata por resíduos de mesotrione, herbicida com mesmo mecanismo de ação do tembotrione, aplicado no ano anterior na cultura do milho (RIDDLE et al. 2013).

Em ambas as épocas avaliadas no presente estudo, não foi detectada diferença no número de hastes, sob o efeito das doses do herbicida, apresentando, em média, 2,25 e 2 hastes por planta aos 60 e 90 DAP, respectivamente (Figura 3A).
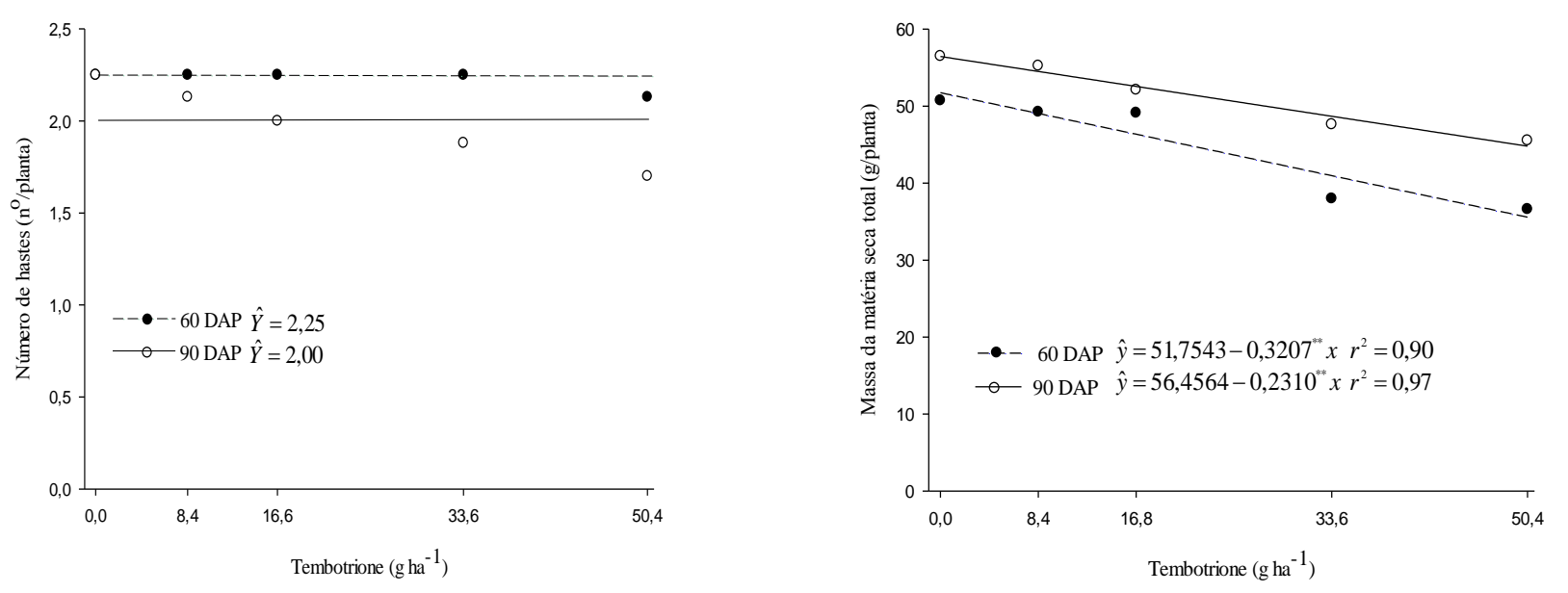

Figura 3. Número de hastes por planta. (A) e massa da matéria seca total (g/planta). (B) de plantas de batata cultivadas em solo com diferentes doses do tembotrione incorporadas.

* Significativo a $1 \%$ pelo teste t. ${ }^{-\bullet-} \mathrm{e}^{-0} 60$ e 90 dias após a plantio (DAP), respectivamente. Figure 3. Number of stems per plant. (A) total dry matter mass (g/plant). (B) number of potatoes grown in soil with different doses of tembotrione incorporated.

** $1 \%$ Significance by $t$ test, respectively. ${ }^{-\bullet}$ and -60 and 90 days after planting (DAP), respectively.

O número de hastes por planta semelhante entre os tratamentos em ambas as avaliações está diretamente relacionado com o tamanho do tubérculo-semente utilizado, bem como com sua condição de brotação ideal no momento do plantio, sendo o mesmo para ambos os tratamentos (SOUZA 2003, FELTRAN \& LEMOS 2005). A densidade do número de hastes não varia após os 30 dias após o plantio, pois essa já está estabelecida (MELO et al. 2003). Corroborando com NOVO \& MIRANDA FILHO (2006), através da simulação de contaminação de tanques de equipamentos de pulverização com sulfonilureias, em que as condições e o tamanho do tubérculo-semente eram iguais, não houve variações no número de hastes por planta. Além do tamanho dos tubérculos-semente, outros fatores interferem diretamente na produção de hastes principais pela batateira, como a idade fisiológica e o número de brotos dos tubérculossemente utilizados, a densidade de plantio, as características do solo da área de cultivo e as condições climáticas durante o ciclo da cultura no campo (BEUKEMA \& ZAAG 1990).

De acordo com MELO et al. (2016) são escassas as informações sobre o comportamento de 
herbicida em solos brasileiros, relacionando com seus possíveis efeitos residuais em olerícolas. Dessa forma, é de suma importância, a bula do herbicida apresentar as restrições sobre determinada molécula. Tais efeitos, como evidenciado no presente estudo, pode comprometer o desempenho agronômico da cultura em campo e acarretar prejuízos aos bataticultores. Além disso, os resultados evidenciam a importância de estudos sobre o comportamento desse herbicida no solo para se garantir a sustentabilidade de cultivos quando utilizados em sucessão à cultura do milho.

\section{CONCLUSÃO}

As aplicações do tembotrione comprometem o desenvolvimento e a produção de massa seca da batateira.

\section{REFERÊNCIAS}

ABIT MJM et al. 2009. Differential response of grain sorghum hybrids to foliar-applied mesotrione. Weed Technology 23: 28-33.

BARCHANSKA H et al. 2016. Degradation study of mesotrione and other triketone herbicides on soils and sediments. Journal of Soils and Sediments 16: 125-133.

BAYER CROPSCIENCE 2017. Bayer CropScience Brasil. Soberan ${ }^{\circledR}$ [Herbicida]. Disponível em: https://www.agro.bayer.com.br/produtos/soberan. Acesso em: 10 jul. 2017.

BEUKEMA HP \& ZAAG D. 1990. Introduction to potato production. Wageningen: Pudac. 208p.

BIEMOND H \& VOS J 1992. Effects of nitrogen on the development and growth of the potato plant. 2. The partitioning of dry matter, nitrogen and nitrate. Annals of Botany 70: 37-45.

CALVAYRAC $C$ et al. 2013. Photolysis of tembotrione and its main by-products under extreme artificial conditions: comparison with another $\beta$-triketone herbicide. Science Total Environment 452-453: 227-232.

CONCEIÇÃO MK et al. 2004. Partição de matéria seca entre órgão de batata-doce (Ipomoea batatas (L.) Lam), cultivares Abóbora e Da Costa. Revista Brasileira de Agrociências 10: 313-316.

EBERLEIN CV \& GUTTIERI MJ. 1994. Potato (Solanum tuberosum) response to simulated drift of imidazolinone herbicides. Weed Science 42: 70-75.

ČEPL J \& KASAL P. 2010. Weed Mapping - A way to reduce herbicide doses. Potato Research 53: 359-371.

EVANGELISTA RM et al. 2011. Qualidade nutricional e esverdeamento pós-colheita de tubérculos de cultivares de batata. Pesquisa Agropecuária Brasileira 46: 953-960.

EMBRAPA. 2013. Empresa Brasileira de Pesquisa Agropecuária. Centro Nacional de Pesquisa Agropecuária de Solos. Sistema brasileiro de classificação de solos. 3.d. Brasília: Embrapa Solos. 342p.

FELTRAN JC \& LEMOS LB. 2005. Características agronômicas e distúrbios fisiológicos em cultivares de batata. Científica 33: 106-113.

HESS FD. 2000. Light-dependent herbicides: an overview. Weed Science 48: 160-170.

IBGE. 2017. Instituto Brasileiro de Geografia e Estatística. Indicadores IBGE: Estatística da Produção Agrícola. Disponível em: ftp://ftp.ibge.gov.br/Producao_Agricola/Fasciculo_Indicadores_IBGE/estProdAgr_201701.pdf. Acesso em: 10 jul. 2017.

LENIS JI et al. 2006. Leaf retention and cassava productivity. Field Crops Research 95: 126-134.

MANCUSO MAC et al. 2011. Efeito residual de herbicidas no solo ("Carryover"). Revista Brasileira de Herbicidas 10: 151-164.

MARIS B. 1988. Correlations within and between characters between and within generations as a measure for the early generation selection in potato breeding. Euphytica 37: 205-224.

MELO CAD et al. 2016. Carryover de herbicidas em sistemas cultivados com olerícolas. Revista Brasileira de Herbicidas 15: 67-78.

MELO PD et al. 2003. Análise do crescimento da cultivar de batata Ágata. Batata Show 3: 16-17.

MILLER JN \& REGEHR DL. 2002. Grain sorghum tolerance to postemergence mesotrione applications. North Central Weed Science Society 57: 136-143.

NOVO MCSS \& MIRANDA FILHO HS. 2006. Tuberização de dois cultivares de batata sob aplicação de sulfoniluréias. Planta Daninha 24: 115-121.

PETER GF \& THORNBER JP. 1991. Biochemical composition and organization of higher plant photosystem II lightharvesting pigment-proteins. Journal of Biological Chemistry 266: 16745-16754.

PRATA F et al. 2003. Glyphosate sorption and desorption in soils with distinct phosphorus levels. Scientia Agricola 60: $175-180$.

REIS MR et al. 2015. Manejo de plantas daninhas do gênero Amaranthus em olerícolas. In: INOUE MH et al. Manejo de Amaranthus. São Carlos: RiMa Editora. p. 173-182.

RIDDLE RN et al. 2013. Crop response to carryover of mesotrione residues in the field. Weed Technology 27: 92-100.

SILVA LAS \& PINTO CABP. 2005. Duration of the growth cycle and the yield potential of potato genotypes. Crop Breeding and Applied Biotechnology 5: 20-28.

SILVA FL et al. 2009. Caracterização morfofisiológica de clones precoces e tardios de batata visando à adaptação a condições tropicais. Bragantia 68: 295-302.

SOUZA ZS. 2003. Ecofisiologia. In: PEREIRA AS \& DANIELS J. (Ed.). O cultivo da batata na Região Sul do Brasil. 


\section{Dias et al.}

Brasília: Embrapa. p.80-105.

TARARA G et al. 2009. Environmental fate of tembotrione. Bayer CropScience Journal 62: 63-78.

TRIGO C et al. 2014. Influence of Soil Biochar Aging on Sorption of the Herbicides MCPA, Nicosulfuron, Terbuthylazine, Indaziflam, and Fluoroethyldiaminotriazine. Journal Agricultural and Food Chemistry 62: 10855-10860.

PPDB. 2017. THE PESTICIDE PROPERTIES DATABASE. Developed by the Agriculture \& Environment Research Unit (AERU). Disponível em: http://sitem.herts.ac.uk/aeru/ppdb/en/Reports/1118.htm. Acesso 10 jul. 2017.

VIVIAN R et al. 2007. Persistência e lixiviação de ametryn e trifloxysulfuron-sodium em solo cultivado com cana-deaçúcar. Planta Daninha 25: 111-124.

WALL DA. 1994. Potato (Solanum tuberosum) response to simulated drift of dicamba, clopyralid, and tribenuron. Weed Science 42: 110-114.

ZELITCH I. 1975. Improving the Efficiency of Photosynthesis. American Association for the Advancement of Science 188: 626-633. 